\title{
ESTIMATIVA DA QUANTIDADE DE RESÍDUOS (CASCA E POLPA) PRODUZIDOS DURANTE O PROCESSO DE BENEFICIAMENTO DO CAFÉ NO MUNICÍPIO DE VARGINHA - MG
}

\author{
Estimation of the amount of residues (bark and pulp) produced during the \\ process of coffee processing in the city of Varginha - MG
}

\author{
Carlos Henrique da Graça \\ Geógrafo, doutorando em Geografia pela Universidade Estadual de Maringá (UEM) \\ henriquechg@gmail.com \\ Rafaela Maria Figueiredo Caldas \\ Graduanda em Geografia pelo Centro Universitário de Maringá (UniCesumar). \\ rafaelamariafigueiredocaldas@hotmail.com
}

\begin{abstract}
RESUMO: O estudo teve como objetivo levantar informações sobre o cultivo e o beneficiamento do café (área colhida e produção média) para estimar a quantidade de resíduos (cascas e polpa) gerados ao longo de sua cadeia produtiva no município de Varginha - Minas Gerais, tendo em vista que esse material é apontado como uma fonte importante de biomassa e pode ser utilizado como matéria-prima para a geração de energia alternativa, além da nutrição do solo e de animais. Para o desenvolvimento do estudo, foram utilizados dados, compreendendo o período de produção de 2004 a 2015, no qual foi aplicada estatística básica para estimar a quantidade de resíduos produzidos entre esses anos. Os resultados mostraram um aumento significativo de $56,2 \%$ na produção de café beneficiado e, proporcionalmente, de resíduos no período analisado entre os anos de 2004 a 2013 e redução nos anos de 2014 e 2015. Esses resíduos, em grande parte, já vêm sendo aproveitados de forma gradativa como substituto da lenha durante o processo de torrefação do café nas indústrias e como adubo orgânico para as lavouras no município. Entretanto, é importante que essas fontes renováveis de matéria-prima sejam manejadas corretamente, pois proporcionam economia tanto para o produtor rural quanto para a indústria, além de benefícios ambientais para a cidade, contribuindo para o aumento da qualidade de vida e possibilitando um desenvolvimento baseado na sustentabilidade.
\end{abstract}

Palavras-Chave: Café, Beneficiamento, Resíduos, Biomassa, Varginha - MG.

ABSTRACT: The objective of this study was to lift information on the cultivation and processing of coffe (harvested area and average yield) to estimate the amount of residues (bark and cellulose) generated along its production chain in the city of Varginha - Minas Gerais. Given that this material is pointed as an importance biomass source and can be used as raw material for alternative energy generation, as well as soil and animal nutrition. For the development of the study, data were used that comprising the production period from 2004 to 2015, in which basic statistics were applied to estimate the amount of waste produced between these years. The results showed a significant increase of $56.2 \%$ in the production of coffee benefited and, proportionally, of waste in the analyzed period between the years 2004 to 2013 and reduction in the years of 2014 and 2015. These residues have been used in large part 
ESTIMATIVA DA QUANTIDADE DE RESÍDUOS (CASCA E POLPA) PRODUZIDOS DURANTE O PROCESSO DE BENEFICIAMENTO DO CAFÉ NO MUNICÍPIO DE VARGINHA - MG.

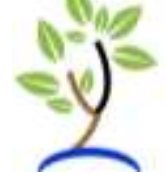

as a substitute for wood during the coffee roasting process in the industry and as an organic fertilizer for the crops in the municipality. However, it is important that these renewable sources of raw materials are managed correctly, since they provide savings for both rural producers and industry, as well as environmental benefits for the city, contributing to the improvement of quality of life and enabling sustainable development.

Key Words: Coffee residues, Coffe processing, Biomass, Varginha - MG.

\section{INTRODUÇÃO}

A crescente demanda energética e a possibilidade iminente de esgotamento das matrizes de origem fóssil nas quais se baseia o consumo mundial ensejam a discussão sobre fontes alternativas de energia. Assim sendo, vem se destacando a utilização da biomassa como um grande potencial perante essas necessidades.

Para Nogueira e Rendeiro (2008), pode ser considerado biomassa todo recurso renovável que provém de matéria orgânica, de origem vegetal ou animal, tendo por objetivo principal a produção de energia. Segundo Paula (2010), a utilização de resíduos de biomassa vegetal para fins energéticos já é uma realidade, porém ainda é um recurso pouco utilizado em âmbito mundial.

A biomassa e seus resíduos são combustíveis sólidos que podem ser utilizados diretamente na condição em que se encontram ou podem ser transformados por processos mecânicos em partículas menores, como cavacos ou serragem, e posteriormente empregados em um processo produtivo, como, por exemplo, na geração de energia (VALE; GENTIL, 2008).

Como biomassa vegetal, destacam-se os resíduos agrícolas, os quais apresentam um alto potencial de energia (WERTHER et al., 2000). Atualmente, a biomassa mais utilizada provém da produção de carvão vegetal (lenha ou resíduos de madeira), muito embora vários estudos venham demonstrando outras fontes potenciais de matéria-prima para a produção, como os resíduos agrícolas, com destaque para as pesquisas desenvolvidas por Suarez e Luengo (2003), Oliveira (2007), Souza et al. (2007), Vale et al. (2007), Silva e Morais (2008), Silveira (2008), Morais et al. (2011) e Lima et al. (2014). 
ESTIMATIVA DA QUANTIDADE DE RESÍDUOS (CASCA E POLPA) PRODUZIDOS DURANTE O PROCESSO DE BENEFICIAMENTO DO CAFÉ NO MUNICÍPIO DE VARGINHA - MG.

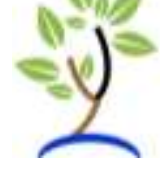

Para Vale et al. (2007), os resíduos de origem florestal e agrícola formam uma categoria interessante de biomassa que pode ser explorada. Segundo Quirino (2003), ao valorizar o resíduo na cadeia produtiva, torna-se possível a eliminação de despesas, além de possibilitar uma renda a mais para a indústria geradora, agregando valor à produção. Brás et al. (2007) completam que, para que as culturas agrícolas tenham fins energéticos, devem ser considerados os seguintes itens: a necessidade de reduzir a dependência energética nacional, a redução de emissão de gases do efeito estufa e maiores opções culturais.

Nesse cenário, o Brasil apresenta condições tanto naturais quanto geográficas favoráveis à produção de biomassa, com destaque em âmbito mundial. Outro importante aspecto a ser considerado é o fato de apresentar uma grande quantidade de terra agricultável, com solos férteis e boas condições climáticas para fomentar a produção da biomassa originada por meio da produção agrícola.

Entre as biomassas de cultivos agrícolas, o bagaço e a palha de cana-deaçúcar detêm a maior representatividade no contexto da agricultura brasileira, sendo aproveitadas em caldeiras para a geração de energia nas usinas, além de o excedente energético ser acrescido ao sistema elétrico (SILVA; MORAIS, 2008). Entretanto, muitas outras culturas apresentam grande potencial para a geração de energia, a exemplo dos resíduos provenientes do arroz, da castanha, do coco, do café e da laranja, entre outros. Dentre as culturas mencionadas com grande potencial energético, chama a atenção o cultivo de café, do qual o Brasil é o maior produtor mundial, com uma produção estimada para o ano de 2016 de 51,4 milhões de sacas beneficiadas (CONAB, 2016).

Com o aumento da produção de café, consequentemente, a quantidade de resíduos agroindustriais também cresce. Estes são fontes reconhecidas de poluição e, se dispostos inadequadamente, podem causar a contaminação de solos e águas (VEGRO; CARVALHO, 1994). No entanto, os resíduos podem deixar de ser um risco e passar a gerar lucro se conduzidos corretamente (VALE; GENTIL, 2008).

Nas lavouras cafeeiras, é gerada uma quantidade de resíduos significativa, na ordem de $45 \%$ do total do café colhido (VENTURIM, 2002), o que torna a palha de REVISTA GEONORTE, V.8, N.30, p.104-117, 2017. (ISSN 2237 - 1419) 
ESTIMATIVA DA QUANTIDADE DE RESÍDUOS (CASCA E POLPA) PRODUZIDOS DURANTE O PROCESSO DE BENEFICIAMENTO DO CAFÉ NO MUNICÍPIO DE VARGINHA - MG.



café uma fonte de recurso natural para o desenvolvimento energético sustentável. A casca do café tem potencial energético que pode substituir a lenha como uma opção mais barata e ecologicamente correta para empresas que usam a madeira na geração de energia (VALE et al., 2007).

A escolha do município de Varginha - MG deu-se em virtude da grande importância que possui no contexto de produção e beneficiamento de café no cenário nacional, sendo também um importante polo exportador do produto. O município apresenta, cerca de, $25 \%$ de sua área cultivada com café, com uma produção média de, aproximadamente, 141 mil sacas (IBGE, 2016).

Diante disso, objetivou-se, neste estudo, levantar informações sobre o cultivo e o beneficiamento do café (área colhida e produção média) para estimar a quantidade de resíduos (cascas e polpa) gerados ao longo de sua cadeia produtiva no município de Varginha - Minas Gerais, tendo em vista que esse material é apontado como uma fonte importante de biomassa e pode ser utilizado como matéria-prima para a geração de energia alternativa, além da nutrição do solo e de animais.

\section{MATERIAIS E MÉTODOS}

O município de Varginha localiza-se na região sul do estado de Minas Gerais (Figura 1), apresentando uma extensão territorial de, aproximadamente, 395.396 km², com população estimada em 132.353 habitantes para o ano de 2015 (IBGE, 2015).

Para o desenvolvimento do trabalho, procedeu-se a uma revisão bibliográfica detalhada acerca do tema proposto, bem como utilizou-se, como base, informações obtidas junto a órgãos institucionais e privados, tais como: Instituto Brasileiro de Geografia e Estatística (IBGE), Companhia Nacional de Abastecimento (CONAB), Prefeitura Municipal de Varginha, Cooperativa dos Cafeicultores da Zona de Varginha (MINASUL). Os dados são referentes aos anos de 2004 a 2015 da produção, do beneficiamento e do descarte ou aproveitamento de resíduos gerados pelo cultivo do café no município de Varginha - MG. Grande parte dessas informações está disponível gratuitamente nos sítios eletrônicos das instituições, contudo foi realizada coleta de 
ESTIMATIVA DA QUANTIDADE DE RESÍDUOS (CASCA E POLPA) PRODUZIDOS DURANTE O PROCESSO DE BENEFICIAMENTO DO CAFÉ NO MUNICÍPIO DE VARGINHA - MG.



informações in loco, especialmente, nas instituições que mantêm sede administrativa no município.

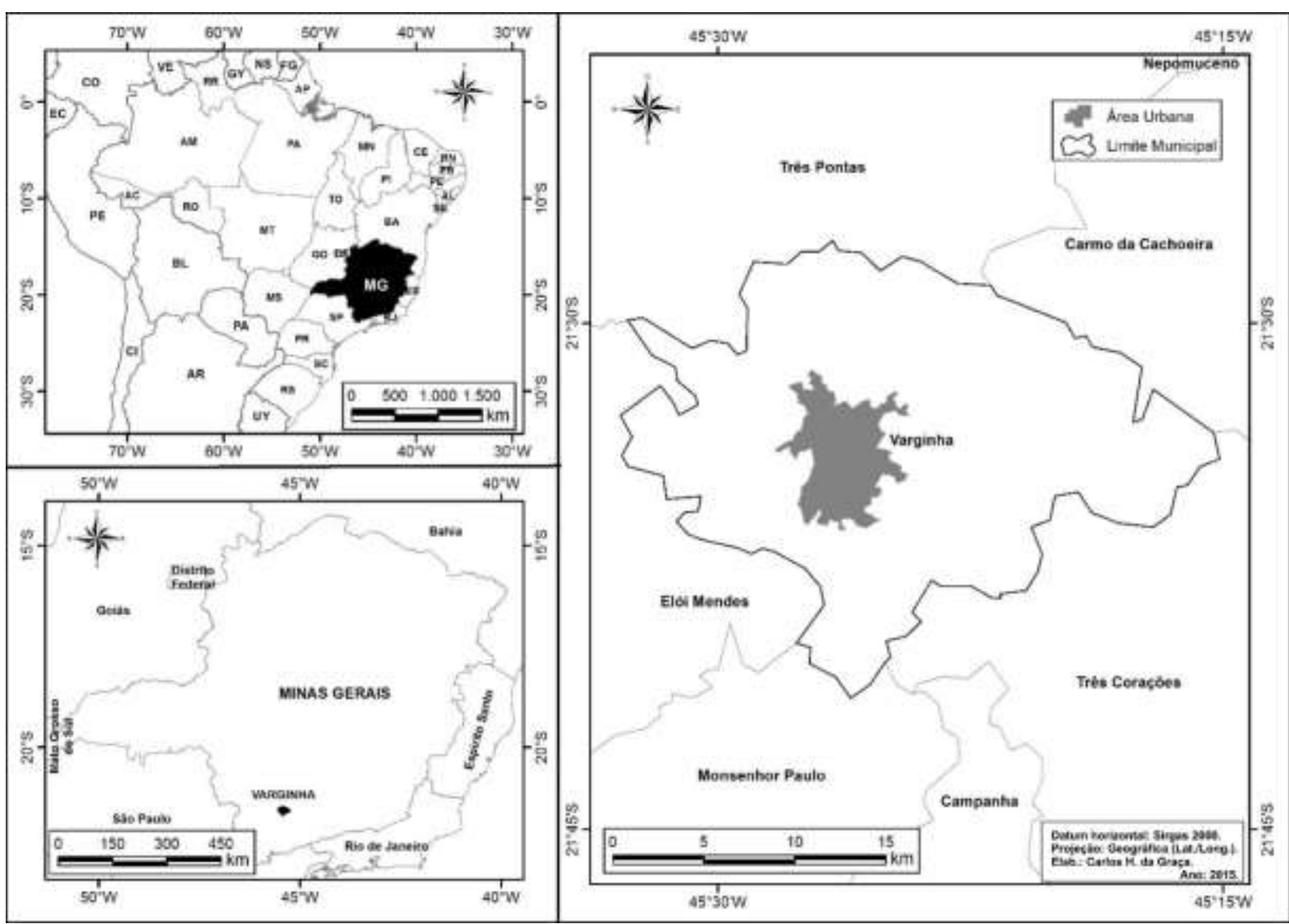

Figura 1 - Localização da área de estudo. (Organização: Autores, 2015).

Para a efetivação de cálculos e a quantificação das informações (dados) obtidas, utilizou-se planilha eletrônica Excel (2007). O cálculo de estimativa de produção de resíduos no município ao longo da série analisada seguiu a proposta de Ferroni e Tuja (1992), que estabelecem que, de posse da área cultivada e da produtividade média por hectare, pode-se estimar a quantidade de café beneficiado (1):

$$
\mathrm{Bcb}=\left(\mathrm{Ac}{ }^{*} \mathrm{Pm}\right){ }^{*} 60
$$


ESTIMATIVA DA QUANTIDADE DE RESÍDUOS (CASCA E POLPA) PRODUZIDOS DURANTE O PROCESSO DE BENEFICIAMENTO DO CAFÉ NO MUNICÍPIO DE VARGINHA - MG.

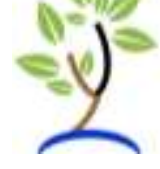

Onde: $\mathrm{Bcb}=$ quantidade de café beneficiado $(\mathrm{kg}) ; \mathrm{Ac}=$ área cultivada; $\mathrm{Pm}=$ produtividade média $(\mathrm{kg} / \mathrm{ha}) ; 60$ = peso da saca de café.

Sabendo que cerca de $45 \%$ do café beneficiado é descartado na forma de resíduo (casca e polpa) (FERRONI; TUJA, 1992), foi possível estimar o total de resíduos gerados no município. Também foram estabelecidos os valores de resíduos gerados durante o beneficiamento no campo e na indústria, referentes aos níveis de geração primário e secundário (MATIELLO et al., 2010).

\section{RESULTADOS E DISCUSSÕES}

A partir do levantamento de informações sobre a área cultivada, a produtividade média do café em coco e o café beneficiado entre os anos de 2004 e 2015, foi possível estimar a quantidade de resíduos produzidos no município de Varginha - MG. A área cultivada/colhida com café entre esses anos teve um acréscimo de 8,6\%, com uma média de 7.318 ha/ano, destacando o ano de 2013 com a maior área cultivada, chegando a 8.120 ha de área (Quadro 1).

Comparando as quantidades produzidas de café beneficiado dentro da série de anos, verificou-se um aumento de $56,2 \%$ na produção entre os anos de 2004 e 2013, visto que, em 2004, a quantidade produzida foi de 7.800 toneladas para 12.180 toneladas no ano de 2013. Nesse período, houve algumas oscilações na produtividade, tendo sido registradas quedas na produção em relação ao ano anterior, representadas pelos anos de 2005, 2007, 2009 e 2011 (Quadro 1).

Ao considerar os anos de 2014 e 2015 em relação ao ano de 2013, ano com a maior produção para a séria analisada, observa-se que houve uma significativa redução na produtividade (Quadro 1), na ordem de 33,7\% e 42,3\%, respectivamente. As oscilações na produtividade registradas ao longo dos anos podem estar atreladas a diversos fatores, mas, de modo geral, verifica-se que o principal fator condicionante para a queda nos índices produtivos é o climático, especialmente em anos com 
ESTIMATIVA DA QUANTIDADE DE RESÍDUOS (CASCA E POLPA) PRODUZIDOS DURANTE O PROCESSO DE BENEFICIAMENTO DO CAFÉ NO MUNICÍPIO DE VARGINHA - MG.

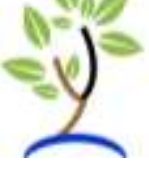

eventos de geadas intensas ou invernos mais rigorosos e/ou em períodos de secas prolongadas (PEREIRA et al., 2008).

Nos anos de 2014 e 2015, a região sudeste do Brasil, onde se encontra o município de Varginha, passou por um momento histórico, com chuvas muito abaixo da média para a região, chegando, em alguns meses, a déficits de $60 \%$ a $70 \%$ (NOBRE et al., 2015), o que contribuiu, significativamente, para a redução na produtividade do café na região.

Quadro 1 - Projeção dos valores de área cultivada, produtividade média do café em coco e café beneficiado no período de 2004 até 2015.

\begin{tabular}{|c|c|c|c|c|c|}
\hline Ano & $\begin{array}{c}\text { Área } \\
\text { cultivada } \\
\text { (ha) }\end{array}$ & $\begin{array}{c}\text { Produtividade } \\
\text { média } \\
(\mathrm{Kg} / \mathrm{ha})\end{array}$ & $\begin{array}{c}\text { Café em coco } \\
\text { (ton) }\end{array}$ & $\begin{array}{c}\text { Café } \\
\text { beneficiado } \\
\text { (ton) }\end{array}$ & $\begin{array}{c}\text { Café } \\
\text { beneficiado } \\
\text { (Sacas de } \\
60 \mathrm{~kg} \text { ) } \\
\end{array}$ \\
\hline 2004 & 6.500 & 2.182 & $14.181,818$ & 7.800 & 130.000 \\
\hline 2005 & 6.500 & 1.636 & $10.636,364$ & 5.850 & 97.500 \\
\hline 2006 & 6.500 & 2.509 & $16.309,091$ & 8.970 & 149.500 \\
\hline 2007 & 6.500 & 1.527 & $9.927,273$ & 5.460 & 91.000 \\
\hline 2008 & 8.100 & 2.182 & $17.672,727$ & 9.720 & 162.000 \\
\hline 2009 & 8.100 & 1.855 & $15.021,818$ & 8.262 & 137.700 \\
\hline 2010 & 6.820 & 2.398 & $16.355,6$ & $8.995,58$ & 149.926 \\
\hline 2011 & 8.072 & 1.964 & $15.850,473$ & $8.717,76$ & 145.296 \\
\hline 2012 & 7.670 & 2.400 & 18.408 & $10.124,4$ & 168.740 \\
\hline 2013 & 8.120 & 2.727 & $22.145,455$ & 12.180 & 203.000 \\
\hline 2014 & 7.870 & 1.865 & 14.676 & 8.072 & 134.530 \\
\hline 2015 & 7.060 & 1.818 & 12.836 & 7.060 & 117.663 \\
\hline Total & -- & -- & $184.020,619$ & $101.211,740$ & 1.686 .855 \\
\hline Média & 7.318 & 2.089 & $15.335,052$ & $8.434,312$ & $140.571,250$ \\
\hline
\end{tabular}

No período de anos analisados, obteve-se um total estimado de 8.809,2 toneladas de resíduos gerados a partir da produção e do beneficiamento do café, com uma média anual de 6.900 toneladas (Tabela 1). No geral, no município houve um acréscimo significativo no montante de resíduos anuais, passando de $6.381,818$ toneladas em 2004 para 9.965,455 toneladas em 2013, e, na indústria, passou de 5.743,636 toneladas em 2004 para 8.968,909 toneladas produzidas em 2013, 
ESTIMATIVA DA QUANTIDADE DE RESÍDUOS (CASCA E POLPA) PRODUZIDOS DURANTE O PROCESSO DE BENEFICIAMENTO DO CAFÉ NO MUNICÍPIO DE VARGINHA - MG.



totalizando cerca de 70.428,9 toneladas de resíduos produzidos nesse período (Tabela 1). Nos anos de 2014 e 2015, houve redução na geração de resíduos, que esteve diretamente relacionada à queda na produtividade média do café no município (Quadro 1).

Em estudo realizado por Matiello et al. (2010) no município, estimou-se que apenas $10 \%$ da produção do café é beneficiada no campo, perfazendo uma menor porcentagem de geração de resíduos na fase primária de produção quando comparado à indústria, que concentra cerca de $90 \%$ do beneficiamento do café. Assim, grande parte dos resíduos gerados no campo, em média 690,077 toneladas anuais (Tabela 1), é utilizada como adubo orgânico nas lavouras.

$\mathrm{Na}$ indústria, o cenário é diferente: os resíduos do café beneficiado têm como principal destino a incineração (combustão) nas fornalhas em substituição à lenha durante o processo de torrefação dos grãos e uma parcela desse resíduo retorna ao campo para ser utilizado como adubo orgânico em lavouras.

Tabela 1 - Estimativa de resíduos sólidos produzidos pós-beneficiamento do café em Varginha/MG no período de 2004 a 2015.

\begin{tabular}{cccc}
\hline Ano & $\begin{array}{c}\text { Resíduos anuais } \\
\text { (ton) }\end{array}$ & $\begin{array}{c}\text { Resíduos anuais } \\
\text { (campo) } \\
\text { (ton) }\end{array}$ & $\begin{array}{c}\text { Resíduos anuais } \\
\text { (indústria) } \\
\text { (ton) }\end{array}$ \\
\hline $\mathbf{2 0 0 4}$ & $6.381,818$ & 638,182 & $5.743,636$ \\
$\mathbf{2 0 0 5}$ & $4.786,364$ & 478,636 & $4.307,727$ \\
$\mathbf{2 0 0 6}$ & $7.339,091$ & 733,909 & $6.605,182$ \\
$\mathbf{2 0 0 7}$ & $4.467,273$ & 446,727 & $4.020,546$ \\
$\mathbf{2 0 0 8}$ & $7.952,727$ & 795,273 & $7.157,454$ \\
$\mathbf{2 0 0 9}$ & $6.759,818$ & 675,982 & $6.083,836$ \\
$\mathbf{2 0 1 0}$ & $7.360,020$ & 736,002 & $6.624,018$ \\
$\mathbf{2 0 1 1}$ & $7.132,713$ & 713,271 & $6.419,442$ \\
$\mathbf{2 0 1 2}$ & $8.283,600$ & 828,360 & $7.455,240$ \\
$\mathbf{2 0 1 3}$ & $9.965,455$ & 996,545 & $8.968,909$ \\
$\mathbf{2 0 1 4}$ & $6.604,2$ & 660,420 & $5.943,780$ \\
$\mathbf{2 0 1 5}$ & $5.776,2$ & 577,620 & $5.198,580$ \\
\hline Total & $\mathbf{8 2 . 8 0 9 , 2 8}$ & $\mathbf{8 . 2 8 0 , 9 2 7}$ & $\mathbf{7 4 . 5 2 8 , 3 5 0}$ \\
\hline Média & $\mathbf{6 . 9 0 0 , 7 7}$ & $\mathbf{6 9 0 . 0 7 7}$ & $\mathbf{6 . 2 1 0 , 6 9 5}$ \\
\hline & & Fonte: Dados da pesquisa. Organização: Autores, 2016.
\end{tabular}


ESTIMATIVA DA QUANTIDADE DE RESÍDUOS (CASCA E POLPA) PRODUZIDOS DURANTE O PROCESSO DE BENEFICIAMENTO DO CAFÉ NO MUNICÍPIO DE VARGINHA - MG.

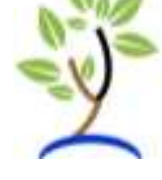

Atualmente, em Varginha, são registradas cerca de 20 indústrias ou empresas que fazem o beneficiamento do café (EMPRESAS DO BRASIL, 2016). Durante o processo de beneficiamento dos grãos de café, são produzidos grandes volumes de resíduos vegetais, principalmente a casca (palha melosa) e o pergaminho (palha voadeira) (VILELLA et al., 2001; OLIVEIRA et al., 2009).

A palha melosa é uma palha mais grossa, escura e úmida com um certo teor de cheiro e gosto de café despolpado; por isso, é destinada à produção de café solúvel, em que passa por vários processos até virar um granulado de café. Palha voadeira é uma palha amarela e seca que, geralmente, é usada nos fornos de secadores de café (combustão) e para a adubação de lavouras, principalmente de cafés orgânicos.

Em alguns casos, quando é produzida a palha melosa, o resíduo é destinado à produção de café solúvel, não sendo uma prática muito comum a todas as indústrias ou empresas de beneficiamento de café local. No município de Varginha, segundo levantamento feito para a pesquisa, existe apenas uma fábrica de café solúvel - Café Solúvel Brasília, que esteve operante nas últimas quatro décadas e, atualmente, faz parte do grupo Três Maria S.A.

Na região Sul de Minas, onde está localizado o município de Varginha, o resíduo do café beneficiado leva o nome de "pó de armazém" ou "resíduo de armazém" e vem se tornando um grande problema associado ao seu aumento em quantidade produzida, pois não há mercado que o absorva, nem um local apropriado para o seu descarte (MIRANDA et al., 2013).

Nas regiões produtoras, esses resíduos têm se tornado um grande problema ambiental, quando mal manejados (MATOS; MONACO, 2003). Segundo Santos e Matos (2000), o acúmulo das cascas dos frutos do café em locais inapropriados por mais de três anos pode causar a contaminação do solo e das águas subterrâneas, com elevadas concentrações de nitrogênio, na forma de amônio e de potássio.

No entanto, a utilização adequada desse subproduto tem inúmeras vantagens, além de sua queima em fornalhas em substituição à lenha e servir de adubo orgânico. REVISTA GEONORTE, V.8, N.30, p.104-117, 2017. (ISSN 2237 - 1419) 
ESTIMATIVA DA QUANTIDADE DE RESÍDUOS (CASCA E POLPA) PRODUZIDOS DURANTE O PROCESSO DE BENEFICIAMENTO DO CAFÉ NO MUNICÍPIO DE VARGINHA - MG.

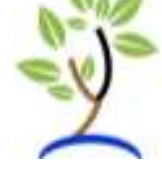

Desse modo, pode ser uma alternativa aos combustíveis fósseis na geração de energia térmica e elétrica, por ser um combustível renovável. Além disso, o resíduo gerado na queima da palha do café (cinzas) possui um alto teor de minerais, podendo ser utilizado pelo produtor rural para a adubação do cafezal, suprindo, assim, parte da adubação química necessária no seu manejo (VALE et al., 2007).

O aumento significativo na produção de resíduos de café em $56,2 \%$ no período de 2004 a 2013 no município evidencia a necessidade da implementação de um sistema eficaz de aproveitamento desse subproduto na forma de biomassa, possibilitando diminuir custos e agregar valores ecológicos à cadeia de produção do café. Desse modo, a utilização de resíduos do café tem que ser vista nos países produtores como uma prioridade, tanto por razões ecológicas como por razões econômicas e sociais.

Na ilha de Cuba, segundo Suarez e Luengo (2003), o uso de casca de café para a produção de energia já é uma realidade, indicando que, nos países em desenvolvimento, a biomassa de resíduo agrícola pode se transformar em uma importante fonte energética para as comunidades.

Um exemplo do quão é viável a utilização dos resíduos da produção e do beneficiamento do café como alternativa de substituição da lenha (carvão vegetal), ou em outros setores da produção, como a geração de energia térmica ou elétrica, é o da indústria Café Bom Dia Ltda., situada na cidade de Varginha - MG, que, desde o ano de 2007, vem promovendo mudanças em sua matriz energética, utilizando uma mescla entre carvão vegetal (eucalipto) e resíduos de café, o que trouxe uma economia de $74 \%$ para a indústria em custos com madeira e, consequentemente, culminou na redução da extração de árvores para esse fim (CAFÉ BOM DIA, 2008).

\section{CONCLUSÕES}

O aproveitamento dos resíduos originados da produção e do beneficiamento de café na cidade de Varginha é uma consequência da alta taxa de produção do café, com uma média anual de 6.900 toneladas de resíduos produzidos no município. 
ESTIMATIVA DA QUANTIDADE DE RESÍDUOS (CASCA E POLPA) PRODUZIDOS DURANTE O PROCESSO DE BENEFICIAMENTO DO CAFÉ NO MUNICÍPIO DE VARGINHA - MG.

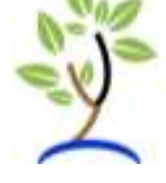

O aproveitamento desse potencial de biomassa ainda é restrito à queima nos fornos de torrefação e na adubação orgânica. Dessa forma, é imprescindível que essas fontes de matéria-prima renovável de baixo custo sejam manejadas corretamente, pois proporcionam economia tanto para o produtor rural como para a indústria, reduzindo o valor gasto na produção de energia para a torrefação. Além disso, agrega-se valor a subprodutos para a cidade, pois gera-se publicidade ambiental para a população varginhense, contribuindo para o aumento da qualidade de vida e possibilitando um desenvolvimento baseado na sustentabilidade.

\section{AGRADECIMENTO}

À Unicesumar - Maringá, pelo incentivo à pesquisa e pelo fomento de bolsa de estudo para o Programa de Iniciação Científica - PIC/ICETI-Unicesumar.

Às indústrias ou empresas que disponibilizaram informações ao desenvolvimento do estudo, em especial, aos Srs. Sebastião Valim e Pedro H. C. Valim.

\section{REFERÊNCIAS}

BRÁS, A. M.; MIRANDA, F.; HIPÓLITO, L.; DIAS, L. S. Biomassa e Produção de Energia. $2007 . \quad$ Disponível em: <http://portal.ipvc.pt/images/ipvc/esa/pdf/biomassa.pdf>. Acesso em: 12/09/2016.

CAFÉ BOM DIA, LTDA. Relatório de Responsabilidade Corporativa. 2008. Disponível em: <http://docplayer.com.br/3629453-Sobre-a-cafe-bom-dia-1consumidores-e-cafe.html>. Acesso em: 05/12/2015.

CONAB (Companhia Nacional de Abastecimento). Safras: séries históricas. Disponível em. < http://www.conab.gov.br/conteudos.php?a=1028>. Acesso em: 29/08/2016. 
ESTIMATIVA DA QUANTIDADE DE RESÍDUOS (CASCA E POLPA) PRODUZIDOS DURANTE O PROCESSO DE BENEFICIAMENTO DO CAFÉ NO MUNICÍPIO DE VARGINHA - MG.

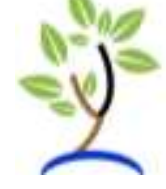
REVISTA GEONORTE

EMPRESAS DO BRASIL. Lista de empresas de beneficiamento de café em Varginha - $\quad$ MG. 2016.2 Disponível em:<http://empresasdobrasil.com/empresas/varginha-mg/beneficiamento-decafe?pagina=1 $>$. Acesso em 09/10/2016.

FERRONI, J.B.; TUJA, F.P. Observações sobre rendimentos e tipo do café em várias misturas de frutos verdes e maduros. Anais... CONGRESSO BRASILEIRO DE PESQUISAS CAFEEIRAS, 18. Araxá (Brasil), Outubro 27-30, 1992.

IBGE (Instituto Brasileiro de Geografia e Estatística). Informações completas: Varginha. 2013. Disponível em: <http://www.cidades.ibge.gov.br>. Acesso em: 12/12/2015.

IBGE (Instituto Brasileiro de Geografia e Estatística). Produção Agrícola Municipal: Varginha. 2015. Disponível em: <http://www.cidades.ibge.gov.br>. Acesso em: 29/03/2016.

LIMA, L. K. S, SANTOS, C. C., MOURA, M. C. F., DUTRA, A. S. D; OLIVEIRA FILHO, A. F.. Utilização de resíduo oriundo da torrefação do café na agricultura em substituição a adubação convencional. Revista ACSA, V. 10, n. 1, p. 14-19, jan - mar, 2014.

MATIELLO, J. B.; SANTINATO, R.; GARCIA, A.W.R.; ALMEIDA, S.R.; FERNANDES, D. R.. Cultura do Café no Brasil: Novo Manual de Recomendações. Varginha-MG: Gráfica e Editora Bom Pastor, 2010. 438p.

MATOS, A.T.; LO MONACO, P.A. Tratamento e aproveitamento agrícola de resíduos sólidos e líquidos da lavagem e despolpa dos frutos do cafeeiro. Viçosa: AEAGRI. 2003. 68p. (Engenharia na Agricultura. Boletim técnico, 7)

MIRANDA, R.V. M.; AMATO, R. M.; PINTO, M. A. M.; FRANCISCO, R. H.; ARAÚJO, J. S. Avaliação da ação alelopática de resíduos do beneficiamento de Coffea arabica I. na germinação de sementes Lactuca sativa L. 2013. In: Anais... 5a JORNADA CIENTÍFICA E TECNOLÓGICA E 2 SIMPÓSIO DE PÓS-GRADUAÇÃO DO IF SUL DE MINAS, Inconfidentes - MG. 2013. 6p.

NOBRE, C.; MARENGO, J. A.; SELUCHI, M. E.; CUARTAS, A.; ALVES, L. M. Some Characteristics and Impacts of the Drought and Water Crisis in Southeastern Brazil during 2014 and 2015. Journal of Water Resource and Protection, v8, 2016. p. 252262.

NOGUEIRA, M. F. M.; RENDEIRO, G.. Caracterização Energética da Biomassa Vegetal. In: BARRETO, E. J. F. (Coord). Combustão e Gaseificação da Biomassa 
ESTIMATIVA DA QUANTIDADE DE RESÍDUOS (CASCA E POLPA) PRODUZIDOS DURANTE O PROCESSO DE BENEFICIAMENTO DO CAFÉ NO MUNICÍPIO DE VARGINHA - MG.
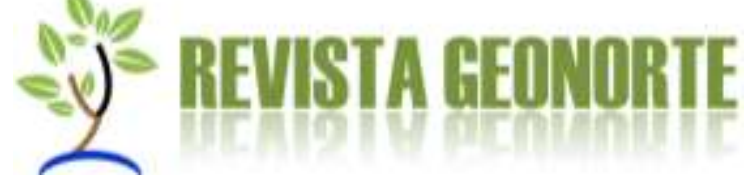

Sólida: Soluções Energéticas para a Amazônia. Brasília: Ministério de Minas e Energia, 2008. p. 52-63.

OLIVEIRA, J. G. Perspectivas para a Cogeração com bagaço de Cana-de-Açúcar: potencial do mercado de carbono para o setor sucro-alcooleiro paulista. Dissertação (mestrado em engenharia de produção), PPEP, Escola de Engenharia de São Carlos da Universidade São Paulo. São Carlos 2007.

OLIVEIRA, R. C. S.; OLIVEIRA, L. S.; FRANCA, A. S.; AUGUSTI, R. A. A preliminary evaluation of the potential of SPME-GC-MS and chemo metrics to detect adulteration of ground roasted coffee with roasted barley. Journal of Food Composition and Analysis, San Diego, v. 22, n. 3, p. 257-261, 2009.

PAULA, L. E. R.. Caracterização química de resíduos lignocelulósicos visando a produção de energia. Anais... ENCONTRO BRASILEIRO EM MADEIRAS E EM ESTRUTURAS DE MADEIRA, Lavras: Instituto Brasileiro da Madeira e das Estruturas de Madeira, 2010.

PEREIRA, A. R.; CAMARGO, A. P.; CAMARGO, M. B. P. Agrometeorologia dos cafezais no Brasil. Campinas: Instituto Agronômico, 2008. 127 p.

SANTOS, J.H., MATOS, A.T. Contaminação do solo em áreas de depósito de cascas de frutos de cafeeiro. In: Anais... I SIMPÓSIO DE PESQUISA DOS CAFÉS DO BRASIL. v.2. Poços de Caldas, 2000, Brasília, p. 981-984. 2000.

SILVA M. B.; MORAIS, A. S. Avaliação Energética do Bagaço de Cana em Diferentes Níveis de Umidade e Graus de Compactação. Anais... XXVIII ENCONTRO NACIONAL DE ENGENHARIA DE PRODUÇÃO. Rio de Janeiro, RJ, Brasil, 13 a 16 de outubro de 2008.

SILVEIRA, M. S. Aproveitamento das cascas de coco verde para Produção de briquete em Salvador - BA. Dissertação (mestrado em Gerenciamento e Tecnologias Ambientais no Processo Produtivo) Escola Politécnica da Universidade Federal da Bahia. Salvador: 2008.

SOUZA, R.C.R; SANTOS, E. C. S.; MORAIS, M. R.; SEYE, O. Carbonização da Casca de Arroz (Oriza sativa) para Uso Energético. Anais... XXXVI CONGRESSO BRASILEIRO DE ENGENHARIA AGRÍCOLA. 30/7 a 2/8. Bonito - MS, 2007.

SUAREZ, J. A.; LUENGO, C. A. Coffee husk briquettes: a new renewable energy source. Energy Sources, [S.I.], v. 25, n. 10, p. 961-967, out. 2003. 
ESTIMATIVA DA QUANTIDADE DE RESÍDUOS (CASCA E POLPA) PRODUZIDOS DURANTE O PROCESSO DE BENEFICIAMENTO DO CAFÉ NO MUNICÍPIO DE VARGINHA - MG.

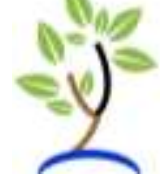

VALE, A. T.; GENTIL, L. V. Produção e uso energético de biomassa e resíduos agroflorestais. In: TECNOLOGIAS APLICADAS AO SETOR MADEIREIRO III. Rio Branco: Suprema, 2008. p.195-241.

VALE, A. T., GENTIL, L. V., GONÇALEZ, J. C., COSTA, A. F. Caracterização energética e rendimento da carbonização de resíduos de grãos de café (Coffea arabica, L) e de madeira (Cedrelinga catenaeformis). Duke CERNE, vol. 13, núm. 4, pp. 416-420, 2007.

VEGRO, C.L.R.; CARVALHO, F.C. Disponibilidade e utilização de resíduos gerados no processamento agroindustrial do café. Informações Econômicas, São Paulo, v.24, n.1, p.9-16, 1994.

VENTURIM, J. B. Gestão de resíduos orgânicos produzidos no meio rural: o caso do beneficiamento do café. Tese (Doutorado em Engenharia da Produção), Programa de pós-graduação em Engenharia de Produção. UFSC, Florianópolis, 2002. 123 f. Disponível em: <http://www.ufsc.br>. Acesso em: 20/03/2015.

VILELA, F. G.; PEREZ, J. R. O.; TEIXEIRA, J. C.; REIS, S. T. Uso da casca de café melosa em diferentes níveis na alimentação de novilhos confinados. Ciência e Agrotecnologia, Lavras, v. 25, n. 1, p. 198-205, jan./fev.2001.

WERTHER, J.; SAENGER, M.; HARTGE, E. U.; OGADA, T.; SIAGI, Z. Combustion of agricultural residues. Progress in energy and combustion science. Alemanha: Pergamon, v.26, p. 1-27, 2000.

Submetido em: 29/06/2017 Aceito para publicação em: 13/11/2017 